\title{
Entre fluxos, fontes e trajetórias: imigração portuguesa para uma capital da Amazônia (1850-1920)*
}

\author{
Between streams, fountains and paths: \\ portuguese immigration for a capital of Amazonia \\ (1850-1920) \\ Entre flujos, fuentes y trayectorias: \\ inmigración portuguesa a una capital de la Amazonia \\ (1850-1920)
}

\author{
Cristina Donza Cancela** \\ João Santos Ramalho Cosme***
}

Resumo: O artigo discute a imigração portuguesa para a capital do Estado do Pará, Belém, no período da economia da borracha. A temática é analisada a partir da problematização do uso das habilitações consulares, observando suas potencialidades e seus limites para o estudo da imigração portuguesa no que diz respeito aos seus números e perfis. E, ainda, cruzar as habilitações consulares com outras fontes para discutir a dinâmica e o trânsito de indivíduos e famílias que aportaram em terras amazônicas.

Palavras-chave: imigração portuguesa; Amazônia; economia da borracha

\footnotetext{
* O presente texto resulta da investigação de pós-doutoramento desenvolvida no Centro de História da Universidade de Lisboa (Bolsa da Coordenação de Aperfeiçoamento de Pessoal de Nível Superior/CAPES) e da Bolsa de Pesquisa em Produtividade do Conselho Nacional de Desenvolvimento Científico e Tecnológico (CNPq).

** Professora associada da Universidade Federal do Pará e do Programa de Pós-Graduação em História da mesma universidade. Doutora em História. Pesquisadora do CNPq e do Grupo de Pesquisa População, Família e Migração na Amazônia-RUMA. $<$ donza6@gmail.com>.

Associate Professor at Universidade Federal do Pará, in the Graduate Program in History. PhD in History. She is a CNPq researcher working in the Research Group Population, Family and Migration in the Amazon - RUMA. <donza6@gmail.com>.

*** Professor auxiliar do Departamento de História da Faculdade de Letras da Universidade de Lisboa. Doutor em História. Pesquisador do Grupo de Pesquisa População, Família e Sociedade - RUMA. <jcosme@letras.ulisboa.pt>.

Adjunct Professor in the Department of History at the Universidade de Lisboa. PhD in History. Researcher in the Research Group Population, Family and Migration in the Amazon - RUMA.<jcosme@letras.ulisboa.pt>.
} 


\begin{abstract}
This paper discusses the Portuguese immigration to Belém, capital of Pará, in the period of the rubber economy. The theme is analysed from the Consular Habilitations; we try to discuss the strengths and the weaknesses of this art of source for the study of Portuguese immigration, especially regarding numbers and profiles. It's also intended to cross-analyse the Consular Habilitations with other sources to understand the dynamics and the paths of individuals and families that arrived in the Amazon lands.

Keywords: portuguese immigration; Amazon; rubber economy

Resumen: El artículo aborda la inmigración portuguesa a la capital del Estado de Pará, Belem, en el período de la economía del caucho. El tema se analiza a través del cuestionamiento del uso de las fichas consulares, señalando su potencial y sus límites para el estudio de la inmigración portuguesa en relación con su número y características. Asimismo, en este trabajo se cruza la información de las fichas consulares con otras fuentes para analizar la dinámica y el tránsito de personas y familias que llegaron a territorio amazónico.
\end{abstract}

Palabras clave: la inmigración portuguesa; Amazon; economía de goma

Sair de sua aldeia em direção ao Brasil. Ir juntamente com um conhecido, um irmão, um pai, ou outro jovem da aldeia, quase da mesma idade, ao Distrito ${ }^{1}$ mais próximo e registrar o pedido de um passaporte para o Brasil. Mas que Brasil? Provavelmente os destinos mais conhecidos: Rio de Janeiro, São Paulo, Santos, Minas Gerais. Os lugares, nomes e caminhos percorridos com maior frequência por diversas gerações de imigrantes portugueses. Contudo, na segunda metade do século XIX, mais precisamente no último quartel daquele século, um número cada vez maior de aldeões, passa a ter escrito em sua trajetória o nome de um lugar: "Pará", ou mesmo, "Cidade do Pará", como também era conhecida a capital daquele Estado, Belém.

Devemos destacar que a presença e ocupação portuguesa na Amazônia, onde se localiza o Estado do Pará, remete ao período colonial (CHAMBOULEIRON, 2010). Contudo, neste artigo, vamos nos concentrar no momento em que essa presença foi estimulada pela economia da borracha, entre os anos de 1850 a 1920, quando a maior liquidez econômica, a implantação e ampliação dos equipamentos e

\footnotetext{
${ }^{1}$ A divisão administrativa de Portugal compreende os "Distritos" que agrupam um certo número de "Concelhos" e têm à frente um representante do governo com funções de caráter administrativo, dentre elas, vale destacar, para fins desse trabalho, a responsabilidade de emissão de passaportes. Os "Distritos" foram instituídos pela Lei de 25 de abril de 1835. Cf: Fernando de Sousa \& Ricardo Rocha. O Distrito de Bragança (1835-2011). cf: <http://www.cepese.pt/portal/pt/investigacao/ working-papers/relacoes-externas-de-portugal/o-distrito-de-braganca-1835-2011/distrito-debraganassa-pdf>. Acesso em: 9 set. 2014.
} 
serviços urbanos, somados à navegação a vapor, atraíram levas de migrantes ${ }^{2}$.

O conceito de migração é aqui entendido como um processo de deslocamento de um país para outro, que pode ocorrer com ou sem a anuência política e burocrática do Estado Nacional. Ela pressupõe a transferência geográfica do indivíduo por um tempo definitivo ou longo, residindo e (re)criando sua experiência, estabelecendo rupturas com o local de origem, mas também continuidades, pois os dois espaços de referência, o antigo e o novo, estão muitas vezes articulados por redes familiares, de amizade, de conterraneidade, atualizadas pelos indivíduos ou pelos grupos e famílias ${ }^{3}$.

No período que estamos tratando ocorre a chamada migração portuguesa moderna, que tem o Brasil como principal destino (PEREIRA, 2002, p. 15-24). Os motivos desse grande fluxo de deslocamentos são, com frequência, descritos pela historiografia que trata do tema. $\mathrm{O}$ crescimento populacional de Portugal, a formação de relações capitalistas na agricultura, na pesca e no artesanato, a não absorção da mão de obra pelo mercado e a indústria lusa, o limite de terra das famílias e as dificuldades de herança, são alguns dos fatores que contribuíram para a miséria, o desemprego e/ou subemprego naquele país, potencializando a migração (SERRÃO, 1974, p. 163-171). Junte-se a isso, as facilidades de transporte de navios e trens, a maior liquidez econômica e o apelo das cidades de destino, para compormos o mosaico de fatores levantados pela historiografia, que nos ajudam a compreender o maior fluxo de migrantes para o Brasil na segunda metade do século XIX ${ }^{4}$.

\footnotetext{
${ }^{2} \mathrm{O}$ comércio da goma elástica se acentua regionalmente, particularmente a partir da década de 1850 , tendo alta no ano de 1860, firmando-se na pauta de exportação a partir de 1870. Desde então, a economia da borracha se consolida ao longo de todo o século XIX e início do XX, entrando em crise a partir do ano de 1911, quando outros produtos ganham maior espaço na lista de exportação, como a castanha-do-Pará (CANCELA, 2011).

${ }^{3} \mathrm{O}$ estudo da migração pressupõe a agência dos sujeitos que migram, suas escolhas e decisões, mas também, os limites e as possibilidades da conjuntura social, econômica e política que dialoga e atravessa as decisões e estratégias individuais e familiares. Vale ressaltar que o emigrante é aquele que sai do país e o imigrante é aquele que chega a um novo país. Sobre essas definições cf. ALVES, 1994, p. 23-24. Neste artigo, o uso do conceito de imigração e emigração tomará como referência a perspectiva de quem reside no Pará, local de destino dos deslocamentos aqui analisados.

${ }^{4}$ É importante ressaltarmos que os deslocamentos migratórios portugueses para o Brasil são anteriores a este período e, pelo menos ao longo do século XVIII, esta imigração já se apresentava. Este fato desencadeou uma política de controle da migração por parte da Coroa Portuguesa, que emitiu seguidas Resoluções, Alvarás e Decretos como tentativa de regulamentar a migração. Como exemplo, temos a Resolução de 16.07.1709, que restringia a partida de indivíduos para terras brasileiras; o decreto de 25.11.1709, que impunha a obrigatoriedade de passaporte para quem fosse viajar para o Brasil; e, finalmente, o Alvará emitido em 1755 que criava a Junta de Comércio a fim de reforçar as medidas de controle comercial (COSME, 2007, p. 07).
} 
Segundo Serrão, esse aumento ocorre particularmente a partir de 1869, alcançando um dos seus picos, no ano de 1895, quando chega à casa dos 44 mil deslocamentos anuais para o Brasil (SERRÃO, 1974, p. 33). Nas primeiras décadas do século XX, esse número diminui para a casa dos vinte mil anuais, para logo aumentar novamente e alcançar a casa dos trinta a quarenta mil, entre os anos de 1905 a 1910, num crescente até o ano de 1913. Volta a diminuir nos anos posteriores variando na casa de vinte mil pessoas anuais, sendo que o ano de 1918, registrou a maior baixa desse período (11. 853 pessoas) e, o ano de 1920, a maior alta (64.783 pessoas anuais), depois de 1913 (77.6454) (SERRÃO, 1974, p. 30-38).

Esses indivíduos vão se deslocar para o Brasil, mas quantos deles têm o Pará como destino? Neste artigo, procuraremos primeiramente analisar o fluxo de entrada de imigrantes portugueses no Pará, no período da economia da borracha, portanto entre os anos de 1850 a $1920^{5}$. Deste modo, capturamos o momento de saída desses sujeitos de um porto português e o momento de chegada ao porto de Belém, compondo um retrato dessa migração. Contudo, seguiremos buscando recuperar não mais o retrato, o instantâneo entre uma chegada e uma saída, mas o trânsito desses imigrantes e seus familiares, seus vários deslocamentos entre aqueles portos e localidades, aproximando e compreendendo fragmentos da trajetória de alguns deles, em particular, de um barão envolvido no comércio de importação e exportação. Seu nome era José Antonio Martins, também conhecido como barão de Monte Córdova. Utilizaremos como fonte habilitações consulares do Pará, registros de passaporte dos Distritos de Braga e de Aveiro, notícias de jornais, testamentos e inventários.

\section{A presença portuguesa no norte do Brasil: Historiografia e fontes}

Um número cada vez mais significativo de trabalhos vem dando visibilidade à presença portuguesa no Brasil. Os estudos acerca desses imigrantes concentraram-se inicialmente no Rio de Janeiro e em São Paulo (MATOS, 2008, p. 101), contudo, há alguns anos, os trabalhos sobre a presença lusa ampliaram-se, compreendendo Estados como Paraná, Rio Grande do Sul e Amazonas (SOUZA e MARTINS, 2007; SOUSA,

${ }^{5}$ A despeito do ano de 1911 marcar a crise da economia da borracha, nos estendemos até o ano de 1920 para percebermos o efeito dessa crise econômica no fluxo de imigrantes alguns anos depois. 
MARTINS e MATOS, 2009; SARGES et al., 2010). No Pará, pesquisas atuais vêm se somar aos trabalhos clássicos realizados na região, no período que estamos tratando. Alguns desses trabalhos clássicos da historiografia amazônica não foram realizados por historiadores e, ainda, embora não tivessem a imigração portuguesa como tema central, tornaram-se referências importantes para o estudo dessa temática. A obra do bacharel em direito, Arthur César Ferreira Reis, com destaque para "O Seringal e o Seringueiro", escrita na década de 1950, analisa o período da borracha e aponta a importância do elemento português nessa economia (REIS, 1972); Já o sociólogo, Samuel Benchimol, reúne textos escritos entre as décadas de 1940 a 1990, sobre os vários povos e etnias que formaram a sociedade e a cultura amazônica, entre elas, o português e sua presença desde o período da Borracha até o ano de 1939 (BENCHIMOL, 2009). O economista Roberto Santos analisou o auge e a decadência da economia da borracha, evidenciando os preços, as taxas de exportação, os investimentos, o processo de decadência da produção gomífera e o movimento de população que ela gerou (SANTOS, 1980). Dentre os trabalhos historiográficos vale citar os produzidos na década de 1980, como a obra da brasilianista Barbara Weinstein, que tinha como foco principal a economia da borracha, mas que não deixava de explorar a presença lusa nessa economia (WEINSTEIN, 1993). Ou ainda, da historiadora e socióloga, Rosa Marin, sobre as relações familiares e de casamento de pessoas ligadas à terra, ao comércio ou à atividades militares e/ou governamentais, no século XIX, dentre eles estavam os portugueses e seus descendentes (MARIN, 1985).

Nos últimos anos, um conjunto de artigos e teses vem abordando diretamente a temática da imigração portuguesa, no período que estamos tratando. O uso de fontes inéditas, a análise do fluxo migratório, o perfil dos imigrantes e a importância da economia da borracha para esses deslocamentos, compõem o eixo comum das recentes investigações. Contudo, para além desse eixo comum, outras questões vão ser enfocadas por esses estudos. Assim, Edilza Fontes aborda a presença portuguesa a partir do trabalho, da cultura e da atuação dos imigrantes no movimento social (FONTES, 2002). Marília Emmi observa a inserção social dos indivíduos e famílias, particularmente na cidade e nas colônias agrícolas (EMMI, 2010). Marcos Carvalho analisa as leis de imigração, a hospedaria dos imigrantes e as instituições associativas por eles criadas (CARVALHO, 2011). Ana Tereza Hidaka analisa os imigrantes empobrecidos e as Associações que os apoiavam (HIDAKA, 2013). 
A despeito dessa produção, algumas perguntas ainda precisam ser feitas e outras cada vez mais densamente respondidas. Embora, como acentuamos, a análise do fluxo imigratório português seja tema comum dos trabalhos mais recentes, ainda nos resta conhecer melhor esses números e os propósitos que geraram a fonte principal na qual eles se baseiam, no caso, as habilitações consulares ${ }^{6}$. Por conta de seus recortes temporais particulares, cada um dos autores/as acima, com exceção de Maria Thereza, utilizou as habilitações consulares e investigou o fluxo migratório em períodos distintos, embora alguns anos se sobreponham. Marília Emmi, abrange os anos iniciais da documentação, entre 1858 a 1860. Carvalho amplia esse período para os anos de 1890 a 1914, e Fontes o expande um pouco mais, cercando os anos de 1884 a 1914. De algum modo, apenas o período de auge e decadência da economia da borracha é contemplado nesses estudos, com exceção de Marília Emmi, que se encarrega do momento inicial de exploração da goma elástica, mas em um período curto de dois anos. Um dos méritos desses trabalhos é o uso pioneiro de uma fonte até então inédita, as habilitações consulares, e o seu tratamento serial e quantitativo realizado com grande fôlego, dado o número significativo de registros encontrados nos períodos por eles tratados.

Contudo, como referido, há ainda algumas questões que precisam ser discutidas. Por exemplo, qual o montante do fluxo dos imigrantes portugueses para o Pará considerando, não apenas o auge e a decadência, mas também o período de formação, portanto, todo o período da economia da borracha tal como consolidado pela historiografia, entre os anos de 1850 a 1920? A análise de todo esse período nos remeteria a novas questões? Qual o potencial e quais os limites das habilitações consulares para a análise de entrada dos imigrantes portugueses no Pará?

Para respondermos a essas perguntas precisamos entender melhor o que eram as habilitações consulares, ampliar o período de análise dos

\footnotetext{
${ }^{6}$ As habilitações consulares constituem-se em livros de registros de súditos portugueses mantidos pelo consulado de cada localidade, e foram criados como uma forma de controle destes nacionais. A manutenção desses registros constituía-se em uma das obrigações do consulado. Trata-se de uma documentação com informações sobre diversos dados do imigrante relativos à: nome, apelido, naturalidade, data de nascimento, estado, profissão, ultima residência no reino, residência no distrito consular, data de chegada, data de matrícula e a forma pela qual justificou a sua nacionalidade. (Ministério dos Negócios Estrangeiros. Documentos apresentados às Cortes. Regulamento Consular Português. Decreto de 20 de março de 1855. P. 259) Com essa conformação de dados, as habilitações consulares permitem a análise serial e quantitativa da imigração, como veremos mais à frente. Além disso não podemos deixar de observar que esses registros serviam como instrumento da política de monitoramento e controle do Estado Português de seus nacionais.
} 
trabalhos anteriores e observar até que ponto os consulados conseguiam ter controle da entrada de seus nacionais. Por que as pessoas iam ao consulado realizar esses registros? Com que propósitos? Para darmos conta dessas perguntas precisamos conhecer um pouco mais essa fonte.

\section{Habilitações consulares e imigração: limites e potenciais}

Portugal sempre manteve o monitoramento e uma legislação restritiva ao deslocamento de sua população, como se pode observar pela expressiva legislação relativa à obrigatoriedade dos passaportes emitidos pelos governos civis de cada distrito ${ }^{7}$. Contudo, para além dos passaportes, o controle dos deslocamentos também era realizado pelos consulados portugueses. Já no ano de 1853, o governo português emitia uma circular obrigando os cônsules a informar semestralmente os indivíduos de todos os sexos, idade e condição, saídos do continente do reino, das ilhas e de possessões ultramarinas, para o Brasil. A informação deveria ser realizada por distrito consular e sintetizada em mapas estatísticos "a fim de se conhecer o movimento de população e até que ponto será nociva ou conveniente a emigração"».

Inúmeras foram as circulares emitidas pelo Governo Português que atribuíam funções de informação e controle da imigração por parte dos consulados. Em uma delas, determinava-se que os capitães de navio deveriam assinar um termo, em que se comprometiam a apresentar seus passageiros ao cônsul residente no Porto de destino de sua embarcação, buscando-se assim, evitar "abuso por parte desses capitães". Os agentes consulares deveriam averiguar a chegada de imigrantes nos navios a fim de verificar a presença de clandestinos. Caberia ainda aos cônsules, supervisionar os contratos de serviço a que estavam sujeitos os imigrantes, podendo a contratação ser realizada e assinada na sede dos Consulados 9 .

\footnotetext{
${ }^{7}$ Os passaportes eram exigidos no reino desde o século XVIII e foram mantidos pelo governo ao longo de todo o século XIX e início do XX, mesmo quando em outros países europeus eles foram suprimidos. Em Portugal, desde pelo menos o ano de 1863, havia não só a exigência do passaporte na legislação, mas também a determinação de que, para migrar, os "menores necessitavam do consentimento dos pais, as mulheres casadas dependiam dos maridos e os funcionários dos seus superiores hierárquicos" evidenciando medidas restritivas portuguesas de mobilidade de sua população (LEITE,1987, p. 466).

${ }^{8}$ Ministério dos Negócios Estrangeiros. Documentos apresentados às Cortes. Regulamento Consular Português. Decreto de 20 de março de 1855. P. 257.

${ }^{9}$ Ministério dos Negócios Estrangeiros. Documentos apresentados às Cortes. Regulamento Consular Português. Decreto de 20 de março de 1855. P. 259.
} 
Pelo menos desde meados do século XIX, os Ministérios do Império e das Relações Exteriores atualizavam a normatização dos vice-consulados do Brasil nos portos de embarque dos migrantes e dos vice-consulados estrangeiros nos pontos de chegada dos imigrantes no Brasil. No ano de 1872, uma Comissão de Inquérito parlamentar portuguesa voltada para a análise da migração, emitiu uma circular endereçada aos cônsules do Brasil, a fim de que estes informassem a situação da migração em seus distritos consulares nos últimos dez anos, observando dados sobre: fluxo, situação de viagem, condições de trabalho, contratos no serviço agrícola, comercial e industrial, questões de saúde, moléstia e óbito.

Para dar conta da emissão dessas informações e do controle de entrada de imigrantes, Portugal mantinha uma expressiva estrutura consular no Brasil. No ano de 1889, por exemplo, o Corpo Consular português contava com 7 consulados, sendo que 6 destes eram de primeira classe ${ }^{10}$, 34 vice-consulados e 39 agências consulares (CASTRO et al, 2006, p. 145). Um desses consulados de primeira classe encontrava-se no Estado do Pará (BRITO, 1994).

A despeito dessa estrutura, as reclamações dos cônsules eram constantes sobre as dificuldades de fiscalização dos imigrantes em função da demanda gerada pelo fluxo e a não obediência da legislação por parte dos imigrados, capitães de navios e agentes alfandegários ${ }^{11}$.

Desse modo, inúmeras eram as dificuldades de manter a política consular portuguesa que passava pelo exercício de funções de informação, controle e fiscalização da imigração por parte dos cônsules e vicecônsules, que tinham também entre suas atribuições a tarefa de realizar o registro civil de nascimento, casamento e óbito; funções notariais associadas ao registro de propriedades, escrituras de transmissão de bens, testamentos e arrecadação de espólios; e, por fim, a matrícula dos súbditos portugueses que deu origem às habilitações consulares ${ }^{12}$.

\footnotetext{
${ }^{10}$ Os cônsules de primeira e segunda classe eram aprovados em concurso público, recebiam vencimentos, tinham a obrigatoriedade de serem portugueses e só eles poderiam vir a ocupar a função de cônsul geral de um país. Os demais eram de terceira classe, ou seja, empregados de comissão, nomeados dentre os comerciantes e proprietários de uma localidade, com vencimentos recebidos a partir do saldo dos emolumentos e taxas consulares. Eram de preferência portugueses, embora fossem admitidos estrangeiros que conhecessem a língua portuguesa. Cf: Ministério dos Negócios Estrangeiros. Regulamento Consular Português. Decreto de 24 de dezembro de 1903. Lisboa: Imprensa Nacional, 1904.p. 11.

${ }^{11}$ Ministério dos Negócios Estrangeiros. Documentos apresentados às Cortes. Regulamento Consular Português. Decreto de 20 de março de 1855.

${ }^{12}$ Ministério dos Negócios Estrangeiros. Regulamento Consular Português. Decreto de 24 de dezembro de 1903. Lisboa: Imprensa Nacional, 1904.
} 
Como já referido anteriormente, as habilitações consulares constituíam-se em livros de registro de imigrantes portugueses levados a efeito pelos consulados, como uma de suas funções obrigatórias ${ }^{13}$. Segundo o regulamento consular, aqueles imigrantes que não fizessem suas inscrições após seis meses de residência na localidade de destino, pagariam além dos emolumentos determinados em tabela, as taxas suplementares pelo atraso ${ }^{14}$. As habilitações consulares conformavam, portanto, uma estratégia de controle e fiscalização da mobilidade dos imigrantes portugueses.

Os livros de registro das habilitações consulares encontrados para o Pará têm como data inicial, o ano de 1858, e vão até o ano de 1959, sendo que o ano de 1912 não foi localizado. Trabalhamos apenas com as habilitações relativas aos anos de 1858 a $1918^{15}$, perfazendo um total de dez mil quinhentos e setenta e seis registros, distribuídos desta forma:

Tabela 1 - Imigração portuguesa para o Pará (1834-1918)

\begin{tabular}{ccc}
\hline Período & Quantidade & \% \\
\hline antes de 1850 & 246 & 2,3 \\
$1850-1864$ & 1.616 & 15,3 \\
$1865-1874$ & 2.687 & 25,4 \\
$1875-1884$ & 1.234 & 11,7 \\
$1885-1894$ & 709 & 6,7 \\
$1895-1904$ & 878 & 8,3 \\
$1905-1914$ & 1.738 & 16,4 \\
$1915-1918$ & 548 & 5,2 \\
sem informação & 920 & 8,7 \\
Total & 10.576 & 100 \\
\hline
\end{tabular}

Fonte: Habilitações consulares 1858-1918.

De acordo com as habilitações consulares, o maior fluxo de chegada de indivíduos no Pará ocorre nos anos iniciais da economia da

${ }^{13}$ Ministério dos Negócios Estrangeiros. Documentos apresentados às Cortes. Regulamento Consular Português. Decreto de 20 de março de 1855. P. 259.

${ }^{14}$ Ministério dos Negócios Estrangeiros. Documentos apresentados às Cortes. Regulamento Consular Português. Decreto de 20 de março de 1855. P. 259. Conferir também Ministério dos Negócios Estrangeiros. Regulamento Consular Português. Decreto de 24 de dezembro de 1903. Lisboa: Imprensa Nacional, 1904, p. 12-13.

${ }^{15}$ Nossa análise se inicia com o ano de 1858, quando temos o primeiro livro de registro, e segue até o ano de 1918, abrangendo dessa forma o período de formação, consolidação, auge e decadência da economia da borracha. Os anos de 1919 a 1920 ainda não foram tratados. É importante ainda destacar duas questões: 1) O fluxo de imigrantes foi analisado a partir do campo onde se registrava a data de chegada do imigrante ao Pará e não a data de sua habilitação; 2) Apesar de iniciarmos com os registros do livro das habilitações consulares do ano de 1858, os imigrantes não faziam esse registro no mesmo ano de sua chegada. Comumente, eles demoravam vários meses ou anos para fazê-lo. Deste modo, o ano do livro inicial é de 1858, mas contém registros de imigrantes que chegaram em anos anteriores a esta data, por isso, a tabela acima inicia com o ano de 1834. 
borracha, entre 1850 a 1874 , quando se tem o registro de cerca de $41 \%$ do total de entrada de portugueses ${ }^{16}$. A partir de 1875 , estes números caem gradativamente. Assim, temos 11,7\% de entrada entre os anos de 1875 e 1884, percentual que declina bruscamente para $6,7 \%$, entre os anos de 1885 e 1894, portanto em pleno auge da economia gomífera. Já nos anos iniciais do século XX, entre 1905 e 1918, esse percentual volta a crescer, apesar de moderadamente em relação aos anos iniciais, para $16,4 \%$, o que acreditamos estar relacionado com a conjuntura que antecede à primeira guerra mundial, pois é nos anos imediatamente anteriores ao conflito que este fluxo aumenta consideravelmente, pois dos $16,4 \%$ de imigrantes que entraram no Pará entre os anos de 1905 a 1918 , cerca de $8 \%$ deles, ou seja, a metade daquele percentual (16,4\%), migraram nos três anos anteriores ao conflito, 1910 a 1913.

Em resumo, a análise dos números encontrados a partir das habilitações consulares, aponta para o fato de que o percentual de imigrantes que chegou ao Pará tendeu a diminuir ao longo do final do século XIX e início do XX. Ou seja, justamente no período de consolidação da economia da borracha, de seu maior auge e liquidez, é que o fluxo de imigrantes portugueses teria diminuído em relação aos anos iniciais daquela economia.

Ora, este dado é distinto daqueles encontrados por Serrão, acima mostrados, que apontam um volume significativo de imigrantes se deslocando de Portugal para o Brasil, justamente ao longo do final do século XIX e nas primeiras décadas do século XX (SERRÃO, 1974, p. 30-38).

Da mesma forma, esses números são distintos do que se tem encontrado para o restante do Brasil (SCOTT, 2010), ou mesmo para o Pará, particularmente quando levamos em conta as entradas de imigrantes a partir dos registros de passaporte, como veremos mais à frente.

Como entender essa distinção? Primeiramente é importante lembrar que as habilitações consulares têm como limite, o fato de não alcançarem os imigrantes que entraram ilegalmente no país. E, ainda, uma parte considerável das habilitações levantadas apresentava um lapso de tempo entre a data de entrada do imigrante e a data de registro no consulado ${ }^{17}$,

\footnotetext{
${ }^{16}$ Os registros encontrados nas habilitações consulares anteriores a essa data não são expressivos, alcançando apenas $2,3 \%$ do total e encontrando-se em anos muitos dispersos.

${ }^{17}$ Para darmos apenas um exemplo do que estamos tratando, este é o caso do comerciante, Manoel João Gonçalves, que chegou ao Pará vindo do Porto no ano de 1862 e se habilitou junto ao consulado, no ano de 1881. Fonte: Habilitação consular Manoel João Gonçalves. Arquivo do Grêmio Literário Português. Banco de dados Grupo de Pesquisa "População, Família e Migração na Amazônia-RUMA"/ Centro de Memória da Amazônia-CMA. Código 5246. Habilitação 5293. Imagem p1450061 Data habilitação: 14/03/1881.
} 
o que nos faz inferir que não havia tanto rigor no controle deste registro, nem urgência dos imigrantes em habilitar-se junto ao órgão consular, podendo alguns deles simplesmente não fazê-lo. Estes fatores podem nos ajudar a entender porque justamente no período de maior imigração para o Brasil, o percentual de entrada de imigrantes das habilitações decresce.

Assim como as habilitações consulares, os registros de passaporte criados para ter o controle dos deslocamentos de pessoas, no reino e fora dele, também não dão conta da totalidade do fluxo migratório. ${ }^{18} \mathrm{~A}$ imigração clandestina não é contabilizada nesses registros. Além disso, por vezes, nos passaportes constava apenas o nome do marido, embora a esposa, os filhos e possíveis parentes, agregados ou criados também estivessem migrando. Todos esses fatores comprometem e subestimam os números da imigração. Mas, a despeito desses limites, os registros de passaporte constituem-se em uma fonte fundamental para o estudo dos fluxos migratórios pela sua longa periodicidade, regularidade e capacidade de análise serial e quantitativa.

Deste modo, quando trabalhamos com os registros de passaporte de um dos principais distritos de origem dos imigrantes que seguiram para o Pará, o distrito de Braga (Cancela, 2009, p. 149-162), percebemos que o principal fluxo de deslocamento de pessoas ocorre justamente nas últimas décadas do século XIX, e na primeira década do século XX.

Tabela 2 - Imigração do Distrito de Braga para o Pará

\begin{tabular}{ccc}
\hline Anos & Quantidade & \% \\
\hline $1868-1874$ & 273 & 7,11 \\
$1875-1884$ & 740 & 19,27 \\
$1885-1894$ & 734 & 19,11 \\
$1895-1904$ & 1.008 & 26,24 \\
$1905-1913$ & 1.086 & 28,27 \\
$1914-1917$ & 0 & 0 \\
Total & 3.841 & 100 \\
\hline
\end{tabular}

Fonte: Livro de passaportes do Arquivo Distrital de Braga (1868-1917) ${ }^{19}$.

Portanto, há um aumento da migração portuguesa do Distrito de Braga para o Pará, nos anos finais do século XIX e início do século XX, coincidindo com o processo de consolidação e auge da

\footnotetext{
${ }_{18}$ Já em 1709 um decreto de 25 de novembro impunha a obrigatoriedade de passaporte para quem fosse viajar para o Brasil a fim de controlar as saídas de portugueses e criar uma série de punições para quem migrasse sem documentação oficial. (COSME, 2007; MONTEIRO, 2011). Ainda assim, a imigração clandestina era intensa, particularmente a partir do Porto de Vigo, região da Galícia, Espanha. (PEREIRA, 1990, p.773)

${ }^{19}$ Agradecemos ao Luiz Valente pelo acesso ao banco de dados sobre o distrito de Braga.
} 
economia da borracha, evidenciando nesse caso, uma tendência completamente diferente daquela encontrada nas habilitações consulares, onde o fluxo de entrada cai em pleno auge da economia da borracha. É bem verdade que os livros de registro de passaporte de Braga, alcançam o período inicial da economia gomífera somente a partir do ano de 1868, diferentemente das habilitações consulares cujo primeiro livro inicia em 1858. No entanto, mesmo com esta ausência, se tomarmos como referência os anos iniciais que se têm para os registros de passaporte de Braga, entre o período de 1868 a 1874, observamos que ele corresponde a $7,11 \%$ do total de passaportes requeridos. De acordo com as habilitações consulares, para esse mesmo período, com três anos a mais de registro, entre 1865 a 1874, esse número chegou a corresponder a cerca de $25 \%$ do total de habilitações requeridas. Ora, esse percentual de cerca de $25 \%$ da emissão de documentos, no caso dos passaportes, só vai ser atingido nos anos finais do século XIX e início do XX, ou seja, no auge da economia da borracha e não no período de formação daquela economia. Observa-se que após o ano de 1913, não há registro da migração do Distrito de Braga para o Pará, portanto, no período que antecede a primeira guerra mundial, e que também corresponde a crise da economia da borracha naquele estado brasileiro.

Em resumo, podemos concluir a partir dos registros de passaporte que, diferentemente daquilo que encontramos na análise das habilitações consulares, o fluxo imigratório para o Pará se intensifica no final do século XIX e início do XX, e não decai, como as habilitações nos fazem supor.

Não temos pretensão de analisar os registros de passaporte neste artigo. Os números acima foram trazidos apenas para servir de apoio ao nosso argumento em relação aos limites e cuidados quanto ao uso das habilitações consulares para a compreensão do fluxo migratório para o Pará.

Mesmo antes de trabalharmos com os passaportes, os limites das habilitações consulares nos chamaram atenção, pois, quando cruzamos esta documentação com outras fontes cotejadas na pesquisa, como inventários, testamentos, jornais e obras sobre a imigração portuguesa no Pará, levantamos uma série de nomes de imigrantes portugueses que não foram encontrados nas habilitações. Muitas dessas pessoas possuíam expressão na província, com negócios e cargos públicos, portanto não eram pessoas sem recursos ou informação, e que provavelmente tinham conhecimento da possibilidade de habilitação consular. 
Some-se a isto o fato, já referido, que as habilitações dizem respeito àqueles portugueses que se deslocaram ao consulado para fazer o registro, o qual, na maior parte dos casos, não era realizado logo à chegada desses imigrantes. Aliás, inúmeros registros eram feitos anos após a chegada ao Brasil. A despeito da legislação e das inúmeras Circulares, o consulado português parecia não possuir controle e poder de coerção tão estreito na obrigatoriedade de registro dos imigrantes recém-chegados. Voltamos a insistir que todas essas questões nos colocam uma questão metodológica importante à medida que nos ajudam a enxergar o limite das habilitações consulares para o estudo do fluxo imigratório português para o Pará. Contudo, isso não significa que devemos simplesmente desprezar este corpo documental. A despeito dos números da imigração estarem subestimados nesta fonte, isso não nos impede de analisar o perfil de idade, sexo e atividade dos portugueses que procuraram o consulado para se regularizar em terras paraenses, e compará-lo com outras fontes.

\section{Rastreando perfis}

Podemos dizer que parcela significativa dos imigrantes que realizaram seus registros era originária das províncias do Douro $(20,4 \%)$ e do Minho $(15,4 \%)^{20}$, seguidos das províncias da Beira Alta $(5 \%)$, Estremadura (3,2\%) Trás os Montes $(2,3 \%)$ e Beira Baixa $(3 \%)^{21}$.

A maioria esmagadora dos imigrantes era formada por homens (98\%) e um número bastante reduzido de mulheres (2\%). Esses homens chegavam majoritariamente na idade entre 20 a 29 anos $(43 \%)^{22}$. Os mais jovens, entre 15 e 19 anos de idade também migravam significativamente $(13 \%)$, assim como aqueles nas faixas etárias mais elevadas entre 30 a 34 anos (16\%). Os homens que se declararam solteiros compunham

\footnotetext{
${ }^{20}$ Portanto, os locais de origem dos imigrantes que aqui se apresentam são muito semelhantes àqueles já encontrados para os imigrantes portugueses que se deslocaram para o restante do Brasil, ainda na segunda metade do século XVIII e, ao longo do século XIX, onde a grande parte advinha das províncias do Douro e do Minho. Acerca deste perfil emigratório na segunda metade do século XVIII. (COSME, 2007; SERRÃO, 1974; SCOTT, 2002).

${ }^{21}$ É importante ressaltar que um número representativo de registros não continha a informação de origem, perfazendo quase a metade deles $48 \%$. Assim, os dados percentuais acima são relativos apenas aos registros em que esta informação estava presente.

${ }^{22}$ Aqui vemos que há uma continuidade em relação ao perfil emigratório dos portugueses que se deslocaram para o Brasil, ainda na segunda metade do século XVIII, não apenas no que diz respeito à majoritária presença masculina, mas também, no que se refere à idade desses imigrantes, visto que, já naquele século, os deslocamentos ocorriam preferencialmente quando eles tinham entre 15 a 29 anos de idade (COSME, 2007, p. 09).
} 
a maior parte (69\%), comparados ao número de casados $(26 \%)$ e ao de viúvos (2\%). Entre as poucas mulheres encontradas nos registros, a maioria era solteira $(70 \%)$, um número menor declarou ser casada $(13 \%)$ ou viúva $(8 \%)^{23}$.

Quando analisamos os setores e atividades exercidas por estes imigrantes portugueses, vemos o predomínio de práticas associadas ao comércio, seja na condição de proprietário de casa comercial, caixeiro, empregado comercial ou vendedor de produtos na rua. Daqueles que declararam a profissão ao fazer o registro consular, 46,4\% estavam envolvidos com atividades comerciais. Um número bastante expressivo, confirmando a forte presença portuguesa nestas atividades verificada em demais trabalhos (CANCELA e BARROSO, 2011, p. 60-67). Outras atividades apareceram em menor escala. Assim, aqueles que estavam envolvidos com a lavoura e a pesca somaram uma pequena parcela, girando em torno de $8,5 \%$. Este dado é curioso se pensarmos que uma das explicações recorrentes que justificam a migração portuguesa é o fortalecimento do capitalismo nos campos e na pesca, a minimização da necessidade de mão-de-obra em função da introdução de máquinas, ocasionando o deslocamento de lavradores e pescadores para as cidades maiores e, também, para fora do país. Seria de se supor que encontraríamos um número considerável de pessoas ligadas às atividades de lavoura e de pesca em nossa amostragem. Até mesmo porque esses profissionais da lavoura e da pesca vão aparecer, em grande proporção, nos registros de passaporte analisados por vários autores (ALVES, 1994, p. 198-199; MONTEIRO, 2000, p. 199-213).

Este pode ser mais um limite das habilitações consulares. Talvez as pessoas envolvidas no comércio tivessem maior recurso para pagar os emolumentos e taxas exigidas pelo consulado, ou maior interesse em regulamentar sua naturalização portuguesa, e meios para fazê-lo, do que aqueles trabalhadores da lavoura e da pesca. Em que medida a falta de controle estreito do consulado, a ausência de patrimônio e de bens, aliada ao custo do registro e a possível desinformação ou ausência de necessidade prática de regularização, não fez com que muitos imigrantes simplesmente não procurassem o consulado para a realização do registro? Sem falar no fato de que os custos das habilitações consulares se sobrepunham aqueles já realizados para a solicitação dos passaportes.

${ }^{23}$ Tal como os registros de origem, os percentuais encontrados para o ano de chegada e idade dos imigrantes é relativo apenas aos registros em que esta informação estava referida. 
Essa questão fica ainda mais evidente quando fazemos o contraponto do perfil das atividades das habilitações consulares com os registros de passaporte de Braga. Nesta documentação, dentre aqueles que declararam algum tipo de atividade, $28 \%$ deles estavam ligados à atividade comercial, enquanto $24 \%$ declarou trabalhar em atividades ligadas à terra e à pesca ${ }^{24}$. Portanto, nos registros de passaporte, $\mathrm{o}$ percentual de imigrantes ligados ao comércio é cerca de $18 \%$ menor do que aquele encontrado nos registros consulares. Por sua vez, o percentual de imigrantes envolvidos na agricultura e na pesca, é cerca de $15,5 \%$ maior. Desse modo, vemos que as pessoas ligadas às atividades comerciais aparecem proporcionalmente em maior número nas habilitações consulares do que nos registros de passaporte. E, se agricultores e pescadores não chegam nem a $10 \%$ dos imigrantes que se registraram no consulado, eles chegam a representar $24 \%$, dos que solicitaram passaporte ${ }^{25}$.

Os números acima apontam para um recorte das habilitações consulares quanto à atividade dos imigrantes que fizeram seu registro junto ao consulado, evidenciando que a maior parte deles estava envolvida com o comércio e que, portanto, poderiam ter mais recursos, patrimônio e interesse na regularização de sua situação junto ao órgão consular. Este órgão, por sua vez, poderia exercer um controle maior junto aos imigrantes que se acreditava possuir patrimônio mais expressivo e recurso para pagar as taxas exigidas para o registro.

É importante destacar que uma das funções atribuídas ao consulado era apoiar os comerciantes, favorecendo a circulação de produtos portugueses nos locais em que estes órgãos se encontrassem, como se pode depreender da regulamentação consular: "deverá o funccionario consular prestar os seus bons officios, aos comerciantes, caixeiros e demais agentes que, residindo ou viajando no districto consular ahi procurarem receber ou satisfazer encomendas de gêneros portugueses proporcionando-lhes quaisquer esclarecimentos que possam facilitar o exito da sua missão" 26 .

Sabemos que cabia também ao consulado a tarefa de certificar e emitir título de nacionalidade, ser depositário de testamentos de súbditos

\footnotetext{
${ }^{24}$ Fonte: Habilitações consulares 1858-1918/Arquivo do Grêmio Literário Português/Banco de dados Grupo de Pesquisa "População, Família e Migração na Amazônia-RUMA"/CNPq; Centro de Memória da Amazônia-CMA.

${ }^{25}$ Banco de dados dos Livros de passaportes do Arquivo Distrital de Braga (1868-1917).

${ }^{26}$ Ministério dos Negócios Estrangeiros. Regulamento Consular Português. Op. cit., p. 36.
} 
portugueses, lavrar escrituras, arrecadar espólios, além de emitir registro civil. Portanto, uma série de serviços associados ao patrimônio e à condição social dos sujeitos que podiam servir de estímulo à inscrição consular, particularmente daqueles que possuíam algum tipo de patrimônio e precisassem legitimá-lo, receber herança, distribuir herança, obter escrituras de bens, iniciar um negócio, enfim, questões associadas ao patrimônio que poderiam atrair com mais frequência os portugueses que possuíssem um volume maior de recursos e/ou estivessem envolvidos em atividades comerciais ${ }^{27}$.

Estes dados evidenciam o cuidado, já reiterado, que temos que ter ao utilizar as habilitações consulares na análise do perfil dos imigrantes que chegaram ao Pará. Embora essa documentação se constitua em uma fonte importante, afinal nos permite realizar um levantamento serial e quantitativo, ela deve ser utilizada tendo em mente os limites apontados acima, relativos tanto ao fato dos números estarem subestimados, particularmente aqueles que compreendem o período de consolidação e auge da economia da borracha; quanto ao fato de que esses registros parecem apresentar um recorte de condição social, sendo mais frequentemente procurado por aqueles portugueses que tinham algum patrimônio.

Todavia, voltamos a ressaltar que a despeito desses limites, as habilitações constituem-se em fonte interessante e a partir delas podemos analisar questões que vão para além do fluxo migratório e de seu perfil. Podemos, por exemplo, capturar fragmentos da trajetória dos sujeitos. Elas podem nos dar acesso ao movimento, ao trânsito desses imigrantes e de várias gerações de sua família. Com elas podemos rastrear as pessoas de uma mesma família que migraram, o ano em que isto ocorreu, a relação de parentesco entre elas, comparar a idade e a condição social de várias gerações de seus membros.

Da mesma forma, com as habilitações consulares temos como observar a condição social de chegada desses imigrantes e, através do cruzamento com outras fontes, perceber em que medida sua condição foi sendo alterada. Imigrantes que chegavam ao Pará como caixeiros, ainda novos, e ao longo dessas viagens, dos anos e dos negócios, iam alterando o status de caixeiro à negociante, de trabalhador em uma casa comercial a proprietário de um estabelecimento.

Pessoas como Manoel Francisco Fernandes Rendeiro, natural da freguesia de Murtosa, concelho de Estarreja. Através de sua habilitação consular ficamos sabendo que chegou ao Pará no ano de 1884, na

\footnotetext{
${ }^{27}$ Ministério dos Negócios Estrangeiros. Regulamento Consular Português. Op. cit., p. 17-34.
} 
condição de caixeiro, solteiro e, ainda, com 20 anos de idade ${ }^{28}$. Cruzando esta fonte com os registros de passaporte do Distrito de Aveiro, nós o encontramos casado, cinco anos depois, no ano de 1889. No registro de passaporte ele declara sua nova condição: negociante ${ }^{29}$.

$\mathrm{O}$ mesmo ocorre com outro imigrante que de caixeiro passa a negociante de borracha e recebe o título de barão. Vamos conhecer um pouco mais dessa história de um barão que morreu demente.

\section{Imigração, trajetória de família e habilitações consulares}

José Antonio Martins, O barão de Monte Cordova não casou, não teve filhos, foi bastante afortunado com o comércio de importação e exportação, perdeu muito dinheiro, conseguiu se reerguer com parcimônia não chegando a alcançar a fortuna antes adquirida ${ }^{30}$. Chegou ao Pará no começo da economia da borracha, momento em que esse produto começava a ganhar vulto na pauta de exportação. Era o ano de 1856, ele tinha $21 \operatorname{anos}^{31}$. A viagem necessitava de toda uma rede familiar para acontecer. Não era barata e precisava de investimento financeiro para adquirir o passaporte, comprar a passagem de navio e, por vezes, pagar a fiança militar ${ }^{32}$.

$\mathrm{O}$ ano de 1856 mal começara, era o dia 13 de janeiro, e a barca Paraense aportava em Belém, vinda da cidade do Porto, localizada ao norte de Portugal. Jose Antonio Martins chegou ao Pará na condição de caixeiro. Nasceu no Concelho de Santo Tirso, Freguesia de Monte Córdova. Seu pai era um capitão de milícias, Jacinto José Martins, e sua mãe, D. Florinda Rosa Martins, cuidava dos serviços

${ }^{28}$ Habilitação consular Manoel Francisco Fernandes Rendeiro. Arquivo do Grêmio Literário Português. Banco de dados Grupo de Pesquisa "População, Família e Migração na AmazôniaRUMA"/Centro de Memória da Amazônia-CMA. Código 6103. Habilitação 6298. Imagem P1510581. Data habilitação: 08/03/1887.

${ }^{29}$ Registro de Passaporte. Arquivo Distrital de Aveiro, livro n. 14, registro n. 452 de 6 de maio de 1889.

${ }^{30}$ Jornal de Santo Thirso. 17 de janeiro de 1907, fl.01.

${ }^{31}$ Habilitação consular José Antonio Martins. Arquivo do Grêmio Literário Português. Banco de dados Grupo de Pesquisa "População, Família e Migração na Amazônia-RUMA"/Centro de Memória da Amazônia-CMA. Código 735. Habilitação 972. Imagem P1430475. Data habilitação: 05/11/1860.

32 Joel Serrão ao analisar a faixa etária dos migrantes portugueses, dentre eles, o que vão para o Brasil, destaca "costume de enviar para ali jovens com idade inferior a 14 anos, com um duplo objetivo: fugir ao serviço militar e tentar fortuna" (SERRÃO, 1974, p. 123). Alves, analisando a migração no Porto oitocentista, pontua o fato de que o emigrante mais frequente é o jovem, entre 13 a 18 anos de idade, particularmente na primeira metade daquela centúria. Esse perfil só vai se alterar a partir de meados da década de 1870 , quando se tem a generalização de todas as idades, embora a migração de mancebos ainda se fizesse presente (ALVES, 1994. p. 188-196). 
domésticos ${ }^{33}$. Os pais ainda viviam quando José Antônio veio para o Pará. Apenas oito anos depois de chegar a este Estado, conseguiu se estabelecer em um prédio sobradado, à rua da Industria, área nobre de Belém. Neste palacete viveu até retornar para Portugal onde faleceu, por demência, na Quinta do Recreio da Palmeira, no ano de $1907^{34}$.

José Antonio Martins não veio sozinho para o Brasil. Ele tinha mais três irmãos, Constantino, Manoel e Tomaz José Martins. Até onde sabemos, dois deles também migraram para o Pará: Constantino e Manoel.

Constantino chegou ao Pará, cerca de onze anos depois do Barão de Monte Córdova. Sua habilitação no consulado português do Pará, data do ano de 1868, tinha então 18 anos de idade, era solteiro e, assim como o irmão, declarou exercer a atividade de caixeiro ${ }^{35}$. Foi a ele que José Antonio Martins concedeu, em testamento, a administração de seus negócios em caso de falecimento ${ }^{36}$.

Do segundo irmão, Manoel, não se sabe quando chegou ao Pará, mas era negociante no Estado e possuía uma firma de consignação de exportação e importação de produtos sob a razão Martins Pinto e Alves. Foi no Pará que depositou seu testamento. Ele faleceu em 17 de março de 1895, na Ilha da Madeira em viagem para Lisboa. Era natural de Portugal e de nacionalidade brasileira ${ }^{37}$.

O barão de Monte Córdova não teve filhos, pelo menos por ele reconhecidos, não deixando descendentes diretos. Contudo, dois sobrinhos seus, filhos de Manoel e Tomás, também migraram para o Pará e trabalharam no comércio de Belém. O nome deles era Armando Martins Pinto e José da Costa Martins. Juntos eles representavam a segunda geração da família a migrar para a cidade de Belém ${ }^{38}$.

${ }^{33}$ Centro de Memória da Amazônia. Fundo: Cartório Odon Rhossard, caixa, C, Ano 1907, Inventário de José Antonio Martins. Testamento transcrito a partir do Inventário de José Antonio Martins.

${ }^{34}$ Centro de Memória da Amazônia. Fundo: Cartório Odon Rhossard, caixa, C, Ano 1907, Inventário de José Antonio Martins.

${ }^{35}$ Habilitação consular Constantino José Antonio Martins. Arquivo do Grêmio Literário Português. Banco de dados Grupo de Pesquisa "População, Família e Migração na Amazônia-RUMA”/Centro de Memória da Amazônia-CMA. Código da habilitação: 1873. Registro 3099. Imagem: p1480814

${ }^{36}$ Centro de Memória da Amazônia. Fundo: Cartório Odon Rhossard, caixa, C, Ano 1907, Inventário de José Antonio Martins. Testamento Transcrito a partir do Inventário de José Antonio Martins.

${ }^{37}$ Centro de Memória da Amazônia. Fundo: Cartório Odon Rhossard, Ano, 1895, Inventário Manoel Jose Martins Pinto.

${ }^{38}$ Habilitação consular Armando Martins Pinto. Arquivo do Grêmio Literário Português. Banco de dados Grupo de Pesquisa "População, Família e Migração na Amazônia-RUMA"/Centro de Memória da Amazônia-CMA. código 9191. Habilitação 2635. Imagem P1000125. Data da habilitação: 07/07/1908. Habilitação consular José da Costa Martins. Arquivo do Grêmio Literário Português. Banco de dados Grupo de Pesquisa "População, Família e Migração na Amazônia-RUMA"/Centro de Memória da Amazônia-CMA. código 9304. Habilitação 1738. Imagem P1040106. Data da habilitação: 22/03/1916. 
A vinda de um sobrinho para atuar no comércio era um aspecto comum a essa migração portuguesa. Se o Barão de Monte Córdova chegou ao Pará, em 1856, quando a economia da borracha iniciava seu processo de ascensão, os sobrinhos, Armando e José, chegaram à capital paraense em 1904 e 1905, respectivamente, portanto, em pleno auge da produção gomífera. Se o Barão de Monte Córdova chegou a Belém com 21 anos de idade, e seu irmão, Constantino José Martins, com 18 anos, os sobrinhos, Armando e José, tinham 23 e 24 anos de idade, respectivamente, quando realizaram suas habilitações no consulado do Pará. Portanto, estes últimos chegaram a Belém com uma idade alguns anos mais avançada, mas ainda assim, dentro da faixa etária de maior peso dos imigrantes, que ia dos 15 aos 29 anos, conforme destacamos anteriormente. No registro, os irmãos Martins chegaram na condição de caixeiros. O sobrinho Armando destaca a atividade de comerciante.

Como dissemos, o barão de Monte Córdova, nunca casou ou teve filhos, já seu irmão Constantino, casou-se com uma paraense, Etelvina de Abreu e Mello, nascida na cidade de Bragança, interior do Pará ${ }^{39}$. O mesmo ocorreu com o sobrinho Armando, que três anos depois de residir na cidade de Belém, casou-se no ano de 1911, com Maria Luisa Veloso ${ }^{40}$. O enlace ocorreu em Belém. Ela tinha 18 anos e ele 26 anos. Embora Maria Luisa Veloso fosse paraense, ela era filha de um comerciante português, Luiz Gonçalves Veloso, proprietário da firma Almeida Martins e Companhia ${ }^{41}$. Percebemos neste enlace aquilo que Truzzi oportunamente chamou de homogamia oculta, ou seja, embora a noiva fosse de naturalidade paraense, ela era filha de pai português, mantendo deste modo o casamento entre famílias de pessoas com a mesma nacionalidade (TRUZZI, 2004).

Temos então a chegada ao Pará da primeira geração da família formada pelo Barão de Monte Córdova, Constantino e Manoel, aportando na cidade de Belém ainda no início da economia da borracha, nos finais dos anos de 1850 e início de 1860. Três irmãos que chegaram na condição de caixeiro, se estabeleceram na Província com firma de consignação e exportação de produtos. Anos mais tarde, a segunda

\footnotetext{
${ }^{39}$ Arquivo da Cúria, Livro de Matrimônios, rolo 5, Folha 5 (f)-(v). Registro de casamento, Basílica de Nazaré.

${ }^{40}$ Centro de Memória da Amazônia, Cartório Privativo de casamento, Registro civil de casamento, ano 1911.

${ }^{41}$ Centro de Memória da Amazônia. Fundo: Cartório Odon Rhossard, Ano 1900, Inventário Luiz Gonçalvez Veloso.
} 
geração da família formada por Armando e José, também realizou esse deslocamento, em pleno desenvolvimento e consolidação da economia da borracha, nos finais do século XIX e início do XX, momento de liquidez econômica, mudança no traçado urbano e expansão demográfica da capital paraense. A abrangência temporal das habilitações consulares nos permite percorrer a trajetória de mobilidade dessa família e, ainda, perceber a continuidade de sua imigração ao longo dos anos e das gerações, a idade em que chegavam, a mobilidade social e a atividade em que estavam envolvidos. Duas gerações de uma família de imigrantes de Santo Thirso que aportaram em Belém, em diferentes momentos da economia da borracha.

Quantos deles permaneceram na capital paraense? Não sabemos ao certo. O Barão voltou para Portugal onde faleceu, assim como seu irmão, Manoel, que faleceu na Ilha da Madeira, em viagem para aquele país. ${ }^{42}$ Constantino casou-se com uma mulher paraense, mas não residia no Pará, voltou para sua cidade natal ${ }^{43}$ onde era reconhecido como um grande comerciante da freguesia de Santo Thirso ${ }^{44}$.

Pelo testamento do barão de Monte Córdova ficamos sabendo que todos os seus herdeiros viviam em Portugal, com exceção do sobrinho Armando, e de dois sobrinhos, José e Manoel (deste último não temos registro de chegada), que continuavam residindo na cidade de Belém do Pará e, deste modo, mantendo o trânsito e as trocas entre as duas cidades.

\section{Considerações finais}

Acreditamos ter mostrado os limites das habilitações consulares para o estudo do fluxo migratório português para o Pará, e a atenção que devemos ter com o uso dessa fonte no que diz respeito ao traçado do perfil desses imigrantes e a sua condição social. Mas, ao mesmo tempo, esse corpo documental possui um papel importante para o estudo da História da Família, à medida que nos auxilia a compor a trajetória de migração de várias gerações de uma mesma família, ao percorrer um período longo de tempo. Provavelmente, famílias envolvidas no comércio, ou por outra, que tinham patrimônio e renda, pois como vimos, são pessoas com este perfil, que possuíam maior presença nas

\footnotetext{
${ }^{42}$ Centro de Memória da Amazônia. Fundo: Cartório Odon Rhossard, Ano 1895, Inventário Manoel Jose Martins Pinto.

${ }^{43}$ Jornal de Santo Thirso, 19.06.1902, fl.02

${ }^{44}$ Jornal de Santo Thirso. 1.05.1902, fl.03.
} 
habilitações consulares, embora essa documentação não se limitasse a elas. De todo modo, esse corpo documental amplia nossa compreensão da dinâmica imigratória portuguesa e as histórias de indivíduos e famílias que estão por detrás dos números de um registro.

\section{Referências}

ALVES, Jorge Fernandes. Os brasileiros: emigração e retorno no Porto oitocentista. Porto, 1994.

BENCHIMOL, Samuel. Amazônia: formação social e cultura. 3. ed. Manaus: Valer, 2009.

BRITO, Eugenio Leitão. História do Grêmio Literário e Recreativo Português. Belém/ Pará, 1994.

CANCELA, Cristina Donza. Imigração portuguesa, casamento e riqueza em Belém (1870-1920) In: SOUSA, Fernando de; MARTINS, Ismênia; MATOS, Maria Izilda. Nas duas margens: os portugueses no Brasil, Porto, Portugal: Afrontamento, 2009. Açaí, 2011.

. Casamento e família em uma capital amazônica (Belém 1870-1920). Belém:

CANCELA, Cristina Donza; BARROSO, Daniel Souza. Imigração portuguesa e casamento: um olhar a partir do gênero, da geração e da atividade (Belém, 1908-1920). In: SARGES, Maria de Nazaré et al. Entre Mares: o Brasil dos portugueses. Belém: Pakatatu, 2010.

. Casamentos portugueses em uma capital da Amazônia. Perfil demográfico, normas e redes sociais. Belém (1891-1920). História, São Leopoldo: Unisinos, v. 15, n. 01, jan./abr. 2011.

CARVALHO, Marcos Antonio de. Bebendo açaí comendo bacalhau: perfil e práticas da sociabilidade lusa em Belém do Pará entre finais do século XIX e início do XX. 2011. Tese (Doutorado em História) - Universidade do Porto, Faculdade de Letras, Departamento de História e de Estudos Políticos e Internacionais, Porto, Portugal, 2011.

CASTRO, Zília Osorio et al. Tratados do Atlântico Sul: Portugal-Brasil 1825-2000. Ministério dos Negócios Estrangeiros/Instituto Diplomático, Portugal, 2006. (Coleção Biblioteca diplomática).

CHAMBOUlEIRON, Rafael. Povoamento, ocupação e agricultura na Amazônia colonial (1640-1706). Belém: Açaí, 2010.

COSME, João dos Santos Ramalho. A emigração portuguesa para o Brasil na segunda metade do século XVIII. Lisboa: Universidade de Lisboa, 2007.

CRUZ, Ernesto. História de Belém. Belém: Universidade Federal do Pará, 1973.

EMMI, Marilia Ferreira. A Amazônia como destino das migraçãos internacionais do final do século XIX ao início do XX: O caso dos Portugueses. In: Anais do XVII Encontro Nacional de Estudos Populacionais - ABEP, Caxambú, Minas Gerais, Brasil, 20 a 24 de setembro de 2010. 
FONTES, Edilza. Preferem-se portugues(as): trabalho, cultura e movimento social em Belém do Pará (1885-1914). 2002. Tese (Doutorado em História) - Universidade de Campinas - UNICAMP, Campinas, 2002.

HIDAKA, Ana Tereza Tomiko Vicente. Os infortúnios da imigração portuguesa: a benemérita liga portuguesa de repatriação (1908-1949). 2013. Dissertação (Mestrado em História Social da Amazônia) - Universidade Federal do Pará - UFPA, Belém, 2013.

LEITE, Joaquim da Costa. Emigração portuguesa: a lei e os números. Análise Social, v. XXIII, n. 3, p. 463-480, 1987.

MARIN, Rosa Acevedo. As alianças matrimoniais na alta sociedade paraense no século XIX. In: Revista Estudos Econômicos, São Paulo, Instituto de Pesquisas Econômicas da Faculdade de Economia e Administração da Universidade de São Paulo (IPE/USP), n. $15,1985$.

MATOS, Maria Izilda. Âncora de emoções: a imigração portuguesa. Cadernos CERU, série 2, v. 19, n. 01, jun. 2008.

MONTEIRO, Isilda. Os passaportes: do enquadramento legal à prática (1855-1926). In: SOUSA, Fernando et al. Um passaporte para a terra prometida. Porto, Portugal: Fronteira do Caos \& CEPESE, 2011. p. 117-136.

MONTEIRO, Miguel. Migrante, Emigrantes e "brasileiros": territórios, itinerários, trajectórias (1834-1926). Fafe, 2000.

PEREIRA, Miriam Halpern. A política portuguesa de emigração (1850-1930). Bauru: Editora da Universidade do Sagrado Coração (EDUSC)/Portugal, Instituto Camões, 2002.

Algumas considerações complementares sobre a política de emigração portuguesa. Análise Social, Lisboa, v. XXV, p. 735-739, 1990.

REIS, Arthur Cézar Ferreira. Síntese de História do Pará. São Paulo: Revista dos Tribunais, 1972.

SANTOS, Roberto. História econômica da Amazônia (1800-1920). São Paulo: T.A. Queiroz, 1980.

SARGES, Maria de Nazaré et al. (Org.). Entre Mares: o Brasil dos portugueses. Belém: Pakatatu, 2010.

SCOTT, Ana Silvia Volpi. Aproximando a metrópole da colônia: família, concubinato e ilegitimidade no noroeste Português (século XVIII e XIX). In: Anais do XIII Encontro da Associação Brasileira de Estudos Populacionais - ABEP, Ouro Preto, Minas Gerais, novembro de 2002.

. Os Portugueses. São Paulo: Contexto, 2010.

SERRÃO, Joel. A emigração portuguesa: sondagem histórica. Lisboa, Portugal: Livros Horizonte, 1974. (Coleção Horizonte, n. 12).

SOUSA, Fernando de Sousa; MARTINS, Ismênia. A emigração portuguesa para o Brasil. Porto: CEPESE; Rio de Janeiro: FAPERJ, 2007.

SOUSA, Fernando de Sousa; MARTINS, Ismênia; MATOS, Maria Izilda (Org.). Nas duas margens: os portugueses no Brasil. Porto, Portugal: Afrontamento, 2009. 
SOUSA, Fernando de Sousa; ROCHA, Ricardo. O Distrito de Bragança (1835-2011). Disponível em: <http:/www.cepese.pt/portal/pt/investigacao/working-papers/relacoesexternas-de-portugal/o-distrito-de-braganca-1835-2011/distrito-de-braganassa-pdf $>$. Acesso em: 9 set. 2014.

TRUZZI, Oswaldo. Redes em processos migratórios. Tempo Social - Revista de Sociologia da USP, São Paulo, v. 20, n. 1, 2004.

WEINSTEIN, Barbara. A borracha na Amazônia: expansão e decadência (1850-1920). São Paulo: HUCITEC/EDUSP, 1993 [1983].

Recebido: 17 de agosto de 2015 Aprovado: 09 de outubro de 2015 